\title{
Effects of valproic acid on the susceptibility of human glioma stem cells for TMZ and ACNU
}

\author{
ZHIYING LI $^{1 *}$, YUN XIA $^{2^{*}}$, XINGYAO BU ${ }^{3}$, DONGYI YANG $^{3}$, YIQIANG YUAN $^{1}$, \\ XIAOHE GUO $^{1}$, GANGZHONG ZHANG ${ }^{1}$, ZHANWEI WANG ${ }^{1}$ and JICHAO JIAO ${ }^{1}$ \\ ${ }^{1}$ Department of Neurosurgery, Zhengzhou No. 7 People's Hospital; ${ }^{2}$ Department of \\ Microbiology and Immunology, Zhengzhou Health School; ${ }^{3}$ Department of Neurosurgery, \\ Henan Provincial People's Hospital, People's Hospital of Zhengzhou University, Zhengzhou, Henan 450000, P.R. China
}

Received December 25, 2016; Accepted February 23, 2018

DOI: $10.3892 / \mathrm{ol} .2018 .8551$

\begin{abstract}
To investigate the effect of valproic acid (VPA) on the susceptibility of glioma stem cells to temozolomide (TMZ) and nimustine (ACNU), the O6-methylguanine-DNA methyltransferase (MGMT) promoter methylation and its expression of MGMT were examined. A total of 3 glioma cell populations were isolated from human glioma tissues, and immunocytochemistry was used to detect the expression of MGMT. VPA inhibition on the growth of the 3 glioma cell populations exposed to various concentrations of TMZ and ACNU was evaluated. Flow cytometry was applied to detect the apoptosis of glioma cells, and a methylation-specific polymerase chain reaction was used to identify methylation of MGMT promoter. Immunocytochemistry results indicated that MGMT was negatively expressed in the G1 population, but positively expressed in the G2 and G3 populations. Cell growth inhibition assays demonstrated that the survival rate in the VPA + TMZ or ACNU groups was decreased compared with that of the TMZ or ACNU alone groups $(\mathrm{P}<0.05)$. As for the apoptotic rate, those in the VPA alone group were increased compared with the control group $(\mathrm{P}<0.05)$, and the rates in the VPA + TMZ or ACNU groups were increased compared with TMZ or ACNU alone groups $(\mathrm{P}<0.05)$. The expression of MGMT remained negative in the G1 population following treatment with VPA, but MGMT expression became negative in the 2 MGMT-positive cell populations (G2 and G3) following VPA treatment. The MGMT promoter in the G1 population was partially methylated in the control group, but was fully methylated following VPA treatment, while the promoters of G2, G3 were unmethylated in the control group and became partially
\end{abstract}

Correspondence to: Professor Xingyao $\mathrm{Bu}$, Department of Neurosurgery, Henan Provincial People's Hospital, People's Hospital of Zhengzhou University, 7 Weiwu Road, Zhengzhou, Henan 450000, P.R. China

E-mail: yiweihn@126.com

*Contributed equally

Key words: glioma stem cells, valproic acid, O6-methylguanine-DNA methyltransferase methylated in the VPA treatment group. Taken together, TMZ and ACNU may suppress the growth of glioma stem cells in vitro in a dose-dependent manner. VPA may enhance the inhibitory effects of various concentrations of TMZ and ACNU on the growth of MGMT-negative/positive cells, particularly on MGMT-positive cell populations. VPA itself may induce the apoptosis of glioma cells, and VPA combined with TMZ or ACNU may enhance TMZ/ACNU-induced apoptosis of glioma stem cells. Furthermore, VPA may also promote the methylation of the MGMT promoter to silence MGMT expression in glioma cells, which may be an important mechanism through which VPA enhances the efficacy of TMZ and $\mathrm{ACNU}$ in targeting glioma stem cells.

\section{Introduction}

Glioma is the most common type of primary tumor of the central nervous system (1). It has been suggested that a small subset of glioma stem cells (GSCs) in glioma tissues, with stem cell-like features, are the cause of glioma initiation and recurrence (2). Additionally, it has been also identified that GSCs have the ability for over-proliferation, self-renewal, multi-directional differentiation and tumor formation, which are activities closely associated with the mechanisms of tumor angiogenesis and chemotherapy/radiotherapy resistance (3). Therefore, they may be a crucial target for glioma treatment and study.

The current standard treatment for patients with glioma consists of microsurgical resection, followed by radiotherapy and chemotherapy. Chemotherapy with concomitant and adjuvant temozolomide (TMZ) improves the median survival and 5-year survival rate in gliomas $(4,5)$. TMZ is the widely recognized anti-glioma drug and commonly used in clinics at present; however, due to its side effects and only low concentrations delivered to the brain, topical interstitial chemotherapy is considered as an important means of comprehensive treatment of glioma (6). In addition, Ommaya intracapsular injection of nimustine (ACNU) is performed to kill tumor cells, as it reaches a sufficient concentration for activity in the brain and has no marked systemic side effects, achieving a clinical benefit (6). ACNU and TMZ, as alkylating agents, modify the O6 position of DNA guanine with methyl groups, eventually leading to cell death $(7,8)$. The DNA repair protein O6-methylguanine-DNA 
methyltransferase (MGMT) is able to remove the methyl group with toxic and mutagenic effects from the O6 position of guanine for O6-methylguanine repair, thereby protecting the cells against the damage of methyl groups; this is the primary cause of cellular resistance to alkylating agents including TMZ and ACNU $(9,10)$. In tumor cells, the expression of MGMT protein is increased and cellular resistance to alkylating agents is more enhanced. MGMT gene promoter methylation may silence the expression of the MGMT gene, therefore the MGMT gene promoter methylation level may be used to assess the sensitivity of alkylating agents for the predictive evaluation of the clinical efficacy of radiotherapy alone compared to radiotherapy combined with chemotherapy $(11,12)$.

Valproic acid (VPA) is a common antiepileptic drug, and used for the treatment and prevention of brain tumor patients with seizures. In addition to its antiepileptic properties, VPA has been documented to inhibit cell proliferation, induce cell differentiation and apoptosis and suppress tumor angiogenesis (13-15).

However, a small number of studies are available on the interaction of VPA and alkylating agents and the effects of VPA on chemotherapy for glioma (16), particularly for the association of VPA and initiation and recurrence of glioma. The present study used GSCs as the target to explore whether VPA affected the susceptibility of human glioma cells for TMZ and ACNU in vitro, and its effects on the MGMT promoter methylation and its expression of MGMT in glioma cells.

\section{Materials and methods}

Specimens. The present study was approved by the Ethics Committee of Zhengzhou No. 7 People's Hospital (Zhengzhou, China). Written informed consent was gained from all participants. A total of 3 glioma stem cell populations were derived from glioma tissue obtained by surgical resection of 3 patients with glioma ( 2 male and 1 female; age, 42-67; median age, $50.23 \pm 6.56)$ in the Department of Neurosurgery, Henan Provincial People's Hospital (Zhengzhou, China) from August 2012 to October 2013. Firstly, the tissue specimens were placed in a centrifuge tube containing $10 \mathrm{ml}$ DMEM medium (Hyclone; GE Healthcare Life Sciences, Logan, UT, USA) supplemented with $10 \%$ fetal bovine serum (FBS; Hyclone; GE Healthcare Life Sciences), and cut into $0.5 \mathrm{~mm}^{3}$ blocks following rinsing with PBS three times. They were then digested in $2 \mathrm{ml}$ trypsin with PBS added to terminate the digestion, and finally mouth pipetted repetitively to produce a monoplast suspension. The suspension was filtered with a $100 \mu \mathrm{m}$ sieve. Following centrifugation at $37^{\circ} \mathrm{C}$ and $120 \mathrm{xg}$ for $5 \mathrm{~min}$, the cells were collected and seeded into $25 \mathrm{~cm}^{2}$ flasks at a density of $5 \times 10^{3}$ cells/flask, then placed in an incubator at $37^{\circ} \mathrm{C}$ and $5 \% \mathrm{CO}_{2}$ and $95 \%$ humidity. The cell growth status and morphological changes were observed under inverted phase-contrast microscope (magnification, $\mathrm{x} 400$ ) each day. The cells at passage 2 or 3 were collected and identified by immunofluorescence staining of the CD133 and nestin markers of the glioma stem cells. Briefly, cell were rinsed in PBS three times and subsequently blocked with $10 \%$ FBS (Hyclone; GE Healthcare Life Sciences) at $37^{\circ} \mathrm{C}$ for $15 \mathrm{~min}$. The cells were incubated with CD133 (catalog no. ab19898, 1:500; Abcam, Cambridge, UK) and nestin (catalog no. ab11306, 1:500; Abcam) primary antibodies overnight at $4^{\circ} \mathrm{C}$. Following washing with PBS three times, slides were incubated with tetramethylrhodamine (TRITC)-conjugated goat anti-rabbit IgG secondary antibody (catalog no. BA1090, 1:20,000; Wuhan Boster Biological Technology, Ltd., Wuhan, China) and TRITC-conjugated goat anti-mouse IgG secondary antibody (catalog no. BA1089, 1:20,000; Wuhan Boster Biological Technology, Ltd.) at room temperature for $1 \mathrm{~h}$. Finally, cells were identified under a fluorescence microscope (magnification, x400; Olympus AX80; Olympus Corporation, Tokyo, Japan).

Immunocytochemical assay. Cells were grown on glass slides as described previously (17). Following fixation with $4 \%$ paraformaldehyde at $37^{\circ} \mathrm{C}$ for $10 \mathrm{~min}$ and washing with PBS three times, the slides were incubated at $37^{\circ} \mathrm{C}$ with $0.5 \%$ Triton $\mathrm{X}-100$, then endogenous catalase activity was blocked in $3 \% \mathrm{H}_{2} \mathrm{O}_{2}$ solution for $15 \mathrm{~min}$ at room temperature and the slides were sealed in 10\% FBS (Hyclone; GE Healthcare Life Sciences). Subsequently, they were incubated with mouse anti-MGMT antibody (catalog no. ZM-0461, 1:100; ZSGB-Bio; OriGene Technologies, Inc., Beijing, China) at $25^{\circ} \mathrm{C}$ for $60 \mathrm{~min}$ and rinsed in PBS three times. Following the addition of $50 \mu 1$ amplification reagent (reagent $\mathrm{A}$; catalog no. AR1024; Wuhan Boster Biological Technology, Ltd.) and $50 \mu \mathrm{l}$ polymerase conjugate (reagent B; catalog no. AR1024; Wuhan Boster Biological Technology, Ltd.) at $37^{\circ} \mathrm{C}$ for $10 \mathrm{~min}$, 3,3'-diaminobenzidine was used as the chromogen. The slides were counterstained with $10 \%$ hematoxylin at $37^{\circ} \mathrm{C}$ for $15 \mathrm{~min}$, differentiated in $0.1 \% \mathrm{HCl}$-ethanol and re-stained blue with $1 \%$ ammonia at $37^{\circ} \mathrm{C}$ for $15 \mathrm{~min}$. Finally, the slides were dehydrated using graded ethanol series (70, 80, 90, 95 and $100 \%$ ethanol). With xylene $(100 \%)$ as the clearing medium, the sections were mounted in neutral resin, observed with a fluorescence microscope (magnification, x20,000) and images were captured.

Viability of glioma stem cells. As described previously (18), glioma stem cells were seeded into 96-well plates at a density of $5 \times 10^{3}$ cells/well, 20 wells of which were subjected to VPA pre-treatment in each plate: A total of $1 \mu 1100 \mathrm{mmol} / \mathrm{l} \mathrm{VPA}$ was added in each well to a final concentration of $1 \mathrm{mmol} / \mathrm{l}$, then the plate was incubated at $37^{\circ} \mathrm{C}$ for $24 \mathrm{~h}$. According to MGMT protein expression, as determined by the immunocytochemical assay, TMZ or ACNU was added to the wells of the VPA-pretreated and VPA-untreated groups in each 96-well plate in a gradient concentration, with each concentration used in four repeated wells. In the MGMT-negative group, the TMZ concentration gradient consisted of 40,80,120, 160 and $200 \mu \mathrm{mol} / 1$, and the ACNU concentration gradient was 20, 40, 60, 80 and $100 \mu \mathrm{g} / \mathrm{ml}$. In the MGMT-positive group, the TMZ gradient concentration consisted of 100, 200, 300, 400 and $500 \mu \mathrm{mol} / 1$, and the ACNU concentration of 50, 100, 150, 200 and $250 \mu \mathrm{g} / \mathrm{ml}$. The plates were incubated at $37^{\circ} \mathrm{C}$ for $72 \mathrm{~h}$, then $10 \mu \mathrm{l}$ CCK-8 (catalog no. C0037; Beyotime Institute of Biotechnology, Haimen, China) was added to each well, followed by incubation at $37^{\circ} \mathrm{C}$ for $2 \mathrm{~h}$. The absorbance was measured by with a microplate reader at $450 \mathrm{~nm}$, and the viability fraction of each group was calculated using the following formula: Viability fraction=absorbance value of experimental group-value of blank group)/(absorbance value of control group-absorbance value of blank group). 
Table I. Methylation-specific amplification primers for the MGMT promoter.

Annealing

Primers

Sequence (5'-3')

Products, bp

temperature, ${ }^{\circ} \mathrm{C}$

\begin{tabular}{ll}
\hline MGMT-M & F: TTTCGACGTTCGTAGGTTTTCGC \\
& R: GCACTCTTCCGAAAACGAAACG \\
MGMT-U & F: TTTGTGTTTGATGTTTGTAGGTTTTGT \\
& R: AACTCCACACTCTTCCAAAAACAAAACA
\end{tabular}

83

59

91

59

MGMT, O6-methylguanine-DNA methyltransferase; F, forward; R, reverse; M, methylated primer; U, un-methylated primer.

Apoptotic rate detection. Subsequent to culture in serum-free DMEM (Hyclone; GE Healthcare Life Sciences), the glioma stem cells were collected and the cell density was adjusted to $2 \times 10^{5}$ cells $/ \mathrm{ml}$. Then, the cells were transferred into 6 culture flasks $\left(25 \mathrm{~cm}^{2}\right)$ and divided into control, VPA, TMZ, VPA + TMZ, ACNU and VPA + ACNU groups. Cells in the VPA, VPA + TMZ and VPA + ACNU groups were treated with $1 \mathrm{mmol} / \mathrm{l} \mathrm{VPA}$. After $24 \mathrm{~h}$, the TMZ and $\mathrm{VPA}+\mathrm{TMZ}$ groups were treated with TMZ, while the ACNU and VPA + ACNU groups were treated with ACNU. MGMT-negative glioma stem cells were subjected to $60 \mu \mathrm{g} / \mathrm{ml}$ ACNU or $120 \mathrm{mmol} / \mathrm{TMZ}$, while the MGMT-positive glioma stem cells were treated with $150 \mu \mathrm{g} / \mathrm{ml} \mathrm{ACNU}$ or $300 \mathrm{mmol} / \mathrm{l}$ TMZ. Appropriate concentrations were selected based on the results of the CCK- 8 assay. Subsequent to treatment for $72 \mathrm{~h}$, the cells were collected and the density was adjusted to $1 \times 10^{6}$ cells $/ \mathrm{ml}$. From this, $195 \mu 1$ cell suspension was removed and placed into a $5 \mathrm{ml}$ flow tube, followed by the addition of $5 \mu \mathrm{l}$ Annexin $\mathrm{V}$ with gentle mixing; after a 3 min interval, $20 \mu \mathrm{l} / \mathrm{ml}$ propidium iodide solution $(10 \mu \mathrm{l})$ was added, and the mixture was incubated for $15 \mathrm{~min}$ at room temperature in a dark room. A total of $300 \mu \mathrm{l}$ PBS was added to the reaction tube, and the mixture was homogenized and analyzed by flow cytometry (FACSCalibur ${ }^{\mathrm{TM}}$; BD Biosciences, Franklin Lakes, NJ, USA). The experiment was repeated three times.

Detection of the expression of MGMT protein. Cells were grown on glass slides as described previously (17) and divided into VPA and control groups. Cells were adherent to the wall following 1 day of culture at $37^{\circ} \mathrm{C}$ in the flasks, and the VPA group was treated with $1 \mathrm{mmol} / \mathrm{l} \mathrm{VPA}$ solution, while the same amount of sterile deionized water was added to the control group. The slides were incubated at $37^{\circ} \mathrm{C}$ for 2 days in a constant temperature incubator, and cells were adhered firmly. The cells were rinsed twice with PBS and fixed with $4 \%$ polylysine for $10 \mathrm{~min}$ at $37^{\circ} \mathrm{C}$. The expression of MGMT protein in glioma stem cells was detected by immunocytochemistry as aforementioned.

DNA extraction and methylation-specific polymerase chain reaction (PCR). When $90 \%$ confluence was reached, glioma stem cells were divided into two groups: VPA and control. Firstly, the VPA group was treated with $1 \mathrm{mmol} / \mathrm{l} \mathrm{VPA}$ solution, while the same amount of sterile deionized water was added to the control group. After 3 days of culturing at $37^{\circ} \mathrm{C}$, the cells were collected by centrifugation at $37^{\circ} \mathrm{C}$ and $1,000 \mathrm{x} \mathrm{g}$ for $10 \mathrm{~min}$. DNA extraction and purification were performed using a Genomic DNA Purification kit (catalog no. K0512; Thermo Fisher Scientific, Inc., Waltham, MA, USA). Following treatment of samples with methylation-specific PCR (MSP), as described previously (19), MGMT gene promoter methylation amplification primers were designed in Invitrogen; Thermo Fisher Scientific, Inc., Waltham, MA, USA) and are summarized in Table I. The optimal PCR amplification system for MGMT gene was established: A $50 \mu \mathrm{l}$ solution with $10 \mu \mathrm{l}$ bead DNA, $1 \mu \mathrm{l}$ Taq DNA polymerase (Takara Biotechnology Co., Ltd., Dalian, China), $1 \mu \mathrm{ldNTP}, 4 \mu \mathrm{l} \mathrm{MgCl}_{2}$, $5 \mu \mathrm{l}$ 10X Buffer, $1 \mu \mathrm{l}$ MGMT methylation primers, $1 \mu \mathrm{l}$ MGMT non-methylation primers and $27 \mu$ l double-distilled water. The PCR amplification conditions were as follows: Following pre-denaturation at $96^{\circ} \mathrm{C}$ for $10 \mathrm{~min}$, the PCR was suspended, and the PCR products were stored into the refrigerator at $4^{\circ} \mathrm{C}$ for $3 \mathrm{~min}$. Followed by the addition of the Taq DNA polymerase, the reaction continued. The PCR amplification was then performed for 40 cycles of $94^{\circ} \mathrm{C}$ for $30 \mathrm{sec}$, $59^{\circ} \mathrm{C}$ for $40 \mathrm{sec}\left(56^{\circ} \mathrm{C}\right.$ for $40 \mathrm{sec}$ in the methylation amplification cycles), $70^{\circ} \mathrm{C}$ for $40 \mathrm{sec}$ and $70^{\circ} \mathrm{C}$ for $10 \mathrm{~min}$. The products were stored at $4^{\circ} \mathrm{C}$ and separated on $1.5 \%$ agarose gel, then observed with a GelDoc-It ${ }^{\circledR} 2$ Imager (UVP, LLC, Phoenix, AZ, USA).

Determination criteria of MGMT gene promoter methylation. If the methylated primer amplification produced positive results and the non-methylated primer amplification reaction was negative; this was considered to indicate complete methylation of the gene. When the methylated and non-methylated primer amplification samples exhibited positive bands, this was considered to be partial methylation of the gene. When the methylated primer amplification reaction was negative and the non-methylated primer amplification reaction was positive, this was determined to indicate negative gene methylation.

Statistical analysis. All data were analyzed using SPSS 18.0 statistical software (SPSS, Inc., Chicago, IL, USA) and expressed as the mean \pm standard deviation. Comparisons between groups were performed using one-way analysis of variance, followed by a Tukey's post-hoc test. $\mathrm{P}<0.05$ was considered to indicate a statistically significant difference.

\section{Results}

Primary culture and identification of glioma stem cells. After $24 \mathrm{~h}$ culture in serum-containing medium, glioma tissue cells began to adhere to the glass surface, exhibiting varied morphologies, including star-like and spindle shaped 

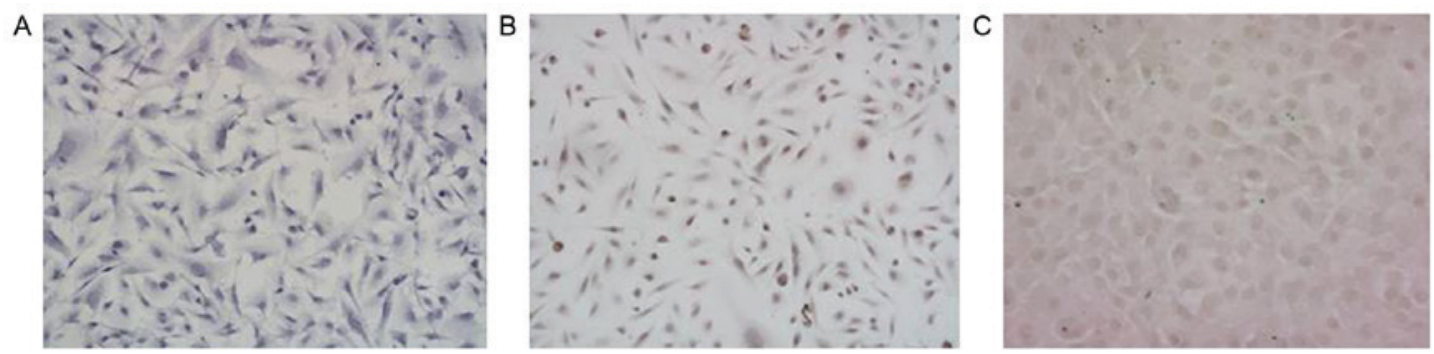

Figure 1. Expression of O6-methylguanine-DNA methyltransferase protein in 3 glioma stem cell populations. (A) G1 cell population. (B) G2 cell population. (C) G3 cell population. Brown-colored particles in the nucleus or cytoplasm indicated the presence of MGMT-positive cells. Magnification, $\mathrm{x} 400$.

cells, prominent cell processes and nuclear abnormalities. After 3-5 days, the cells grew in a single layer, presenting as spindle-shaped in a fence-like pattern into a network. When the cells covered the bottom, small bulges appeared. Immunocytochemistry detecting CD133 and nestin markers of the glioma stem cells indicated that CD133 appeared in the cell membrane, while nestin was expressed in the cytoplasm. In addition, observation by fluorescence microscopy demonstrated that the area exhibiting CD133 positive-expression was green, the nestin positive-expression area was red and the nucleus was blue with DAPI staining. Following fixation with paraformaldehyde, the cell morphology became irregular, but the cells expressed CD133 and nestin. Finally, the 3 cell types expressing CD133 and nestin were named G1, G2 and G3 by immunofluorescence staining.

Expression of MGMT protein in glioma stem cells. The presence of brown-colored particles in the nucleus or cytoplasm was identified as MGMT-positive expression by immunocytochemical detection. As indicated in Fig. 1, in the 3 glioma stem cell populations (G1, G2, G3), the immunocytochemistry results demonstrated that MGMT was negatively expressed in G1, but positively expressed in G2 and G3 (Fig. 1).

Detection of glioma cell viability. The absorbance values of each group were measured by ELISA to calculate the viability of the glioma stem cells. As indicated in Fig. 2, the survival rate of the 3 glioma cells exposed to the various concentrations of TMZ or ACNU in VPA + TMZ/ACNU groups was decreased compared with that of the TMZ or ACNU alone group $(\mathrm{P}<0.05)$. There was a particularly significant difference in cells exposed to lower concentrations of TMZ or ACNU compared with cells exposed to higher TMZ/ACNU concentrations $(\mathrm{P}<0.05)$, which indicated that VPA at various concentrations enhanced the inhibitory effects of TMZ and ACNU on the growth of MGMT-negative/positive cells (Fig. 2), in particular in the MGMT-positive cells (G2 and G3) (Fig. 2C-F).

VPA combination with TMZ/ACNU increases the apoptotic rate of glioma stem cells. In the MGMT-negative glioma cells (G1) or MGMT-positive cell (G2, G3), the apoptotic rate of the VPA alone group was increased compared with that of the control group $(\mathrm{P}<0.05)$, indicating that VPA induced the apoptosis of glioma stem cells. Additionally, the apoptotic rate in glioma cells exposed to VPA combined with TMZ or ACNU was increased compared with that of cells treated with $\mathrm{TMZ}$ or ACNU alone $(\mathrm{P}<0.05)$, and there was a significant difference in the MGMT-positive cells, compared with the MGMT-negative cells $(\mathrm{G} 2, \mathrm{G} 3)(\mathrm{P}<0.05)$, which suggested that VPA combined with TMZ or ACNU may increase TMZ/ACNU-induced apoptosis of glioma stem cells, particularly in MGMT-positive cells (Table II).

VPA downregulates the expression of MGMT protein. As demonstrated in Fig. 3, the MGMT-negative G1 cells were cultured in medium containing $1 \mathrm{mmol} / 1$ VPA for 3 days. MGMT remained negatively expressed in the G1 line, but MGMT expression appeared negative in the 2 MGMT-positive cell populations (G2 and G3) following exposure to $1 \mathrm{mmol} / \mathrm{l}$ VPA for 3 days, indicating that VPA may downregulate the expression of MGMT in MGMT-positive cell populations.

VPA promotes the methylation of MGMT promoter. As indicated in Fig. 4, the MGMT promoter methylation assays revealed that the MGMT promoter of G1 was partially methylated in the control group, but that the promoter became fully methylated in the VPA treatment group following VPA treatment. Concurrently, the promoters of G2 and G3 were unmethylated in the control groups, but were partially methylated in the VPA treatment groups, which indicated that VPA may promote the methylation of the MGMT promoter and silence MGMT expression in glioma cells.

\section{Discussion}

TMZ and ACNU are components of standard chemotherapeutic schedules for the first-line treatment of malignant gliomas. However, these alkylating agents do not exhibit the same levels of efficacy in all glioblastomas, and certain glioma cells exhibit alkylating agent resistance, which has been demonstrated to be correlated with DNA repair protein O6-methylguanine-DNA methyltransferase (MGMT) expression (10). Alkylating agents may also modify the O6 position of DNA guanine with methyl groups, eventually leading to cell death dues to failure of mitosis $(7,8)$. In addition, MGMT is able to remove the methyl group with toxic and mutagenic effects from the O6 position of guanine for O6-methylguanine repair, therefore protecting the cells against the damage of methyl groups $(9,10)$. CpG methylation of the MGMT promoter may inhibit MGMT expression, and almost one-half of primary glioblastoma samples have evidence of high promoter methylation, as determined by methylation-specific PRC (20,21). Furthermore, among patients with glioma treated with TMZ combined with radiation, there is significant difference in the 2-year survival of patients with 


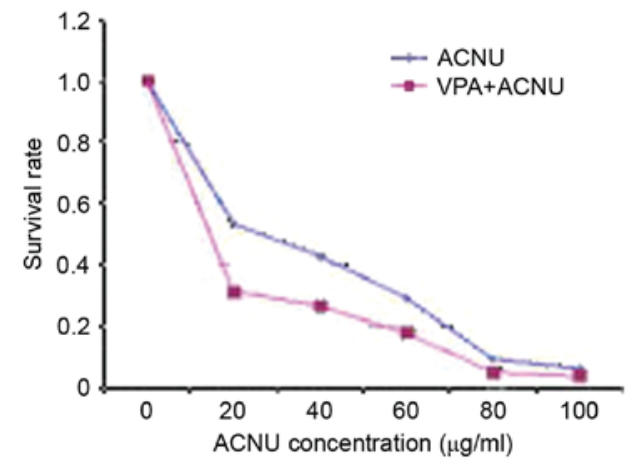

C
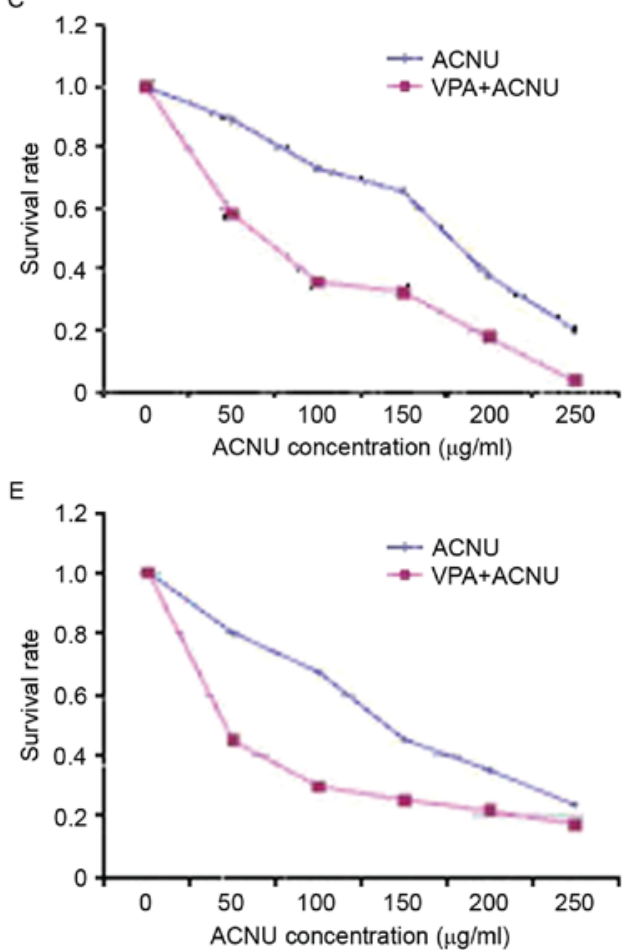
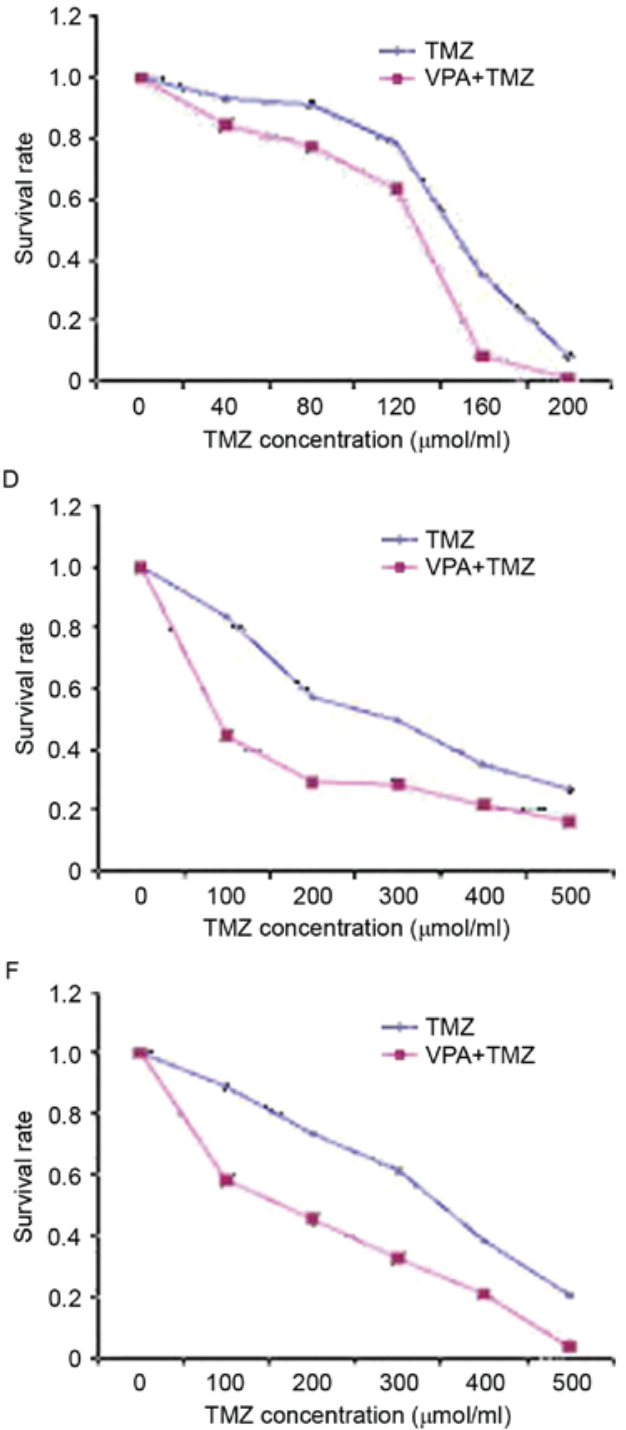

Figure 2. Comparison of the viability of glioma stem cells in each group. (A) Administration of ACNU alone and administration of VPA + ACNU in combination in the G1 cell population. (B) Administration of TMZ alone and administration of VPA + TMZ in combination in the G1 cell population. (C) Administration of ACNU alone and administration of VPA + ACNU in combination in the G2 cell population. (D) Administration of TMZ alone and administration of VPA + TMZ in combination in the G2 cell population. (E) Administration of ACNU alone and administration of VPA + ACNU in combination in the G3 cell population. (F) Administration of TMZ alone and administration of VPA + TMZ in combination in the G3 cell population. ACNU, nimustine; VPA, valproic acid; TMZ, temozolomide.

MGMT promoter hypermethylation (46\%) as compared with those without evidence of tumor hypermethylation (14\%) (22). Therefore, a decrease in the expression of MGMT as a result of MGMT promoter hypermethylation in glioma cells may enhance the sensitivity of these cells to alkylating agents, which is valuable for future studies.

It has been documented that VPA exhibits anti-glioma effects due to its inhibition of histone deacetylase (23). In addition, VPA may induce glioma cell differentiation and apoptosis, and inhibit glioma proliferation, invasion and angiogenesis (24). However, its sensitivity varies among malignant glioma cell populations. For example, VPA has an anti-cancer effect in U87 and U251 cells at low dosages, while VPA has the similar effects on T98 and U138 cells at higher dosages (25). Numerous in vitro studies have used concentrations of VPA ranging from 1-10 mM (26,27). The present study used a dosage of $1 \mathrm{mM}$, as this concentration was close to the concentration $(0.5-1 \mathrm{mM})$ that may be achieved in vivo. The glioma stem cells in the present study were isolated and cultured from the tumor specimens excised from patients with glioma, as glioma stem cells are the cause of the development and recurrence of glioma, and cells from tumor tissues may provide an accurate reflection of the overall biological characteristics of the tumor.

In the present study, the results indicated that VPA enhanced the inhibitory effects of TMZ and ACNU at various concentrations on the growth of MGMT-negative/positive cells, particularly in the MGMT-positive cell populations. Flow cytometry used to measure the levels of apoptosis indicated that VPA alone induced the apoptosis of glioma cells, and VPA combined with TMZ or ACNU increased the rate of TMZ/ACNU-induced apoptosis of glioma stem cells, particularly in MGMT-positive cells compared with VPA treatment alone. The immunocytochemistry results 
Table II. Percentage of apoptotic cells in each group.

\begin{tabular}{lrccccc}
\hline Glioma cells & Control group, $\%$ & VPA, $\%$ & TMZ, $\%$ & VPA+TMZ, $\%$ & ACNU, \% & VPA+ACNU, \% \\
\hline G1 & $16.86 \pm 2.31$ & $21.14 \pm 1.01^{\mathrm{a}}$ & $27.72 \pm 2.29$ & $35.16 \pm 0.45$ & $26.33 \pm 0.65$ & $28.51 \pm 1.06$ \\
G2 & $7.02 \pm 2.84$ & $17.49 \pm 1.54^{\mathrm{a}}$ & $18.42 \pm 1.47$ & $43.44 \pm 0.93^{\mathrm{b}}$ & $15.99 \pm 1.29$ & $30.42 \pm 1.64^{\mathrm{b}}$ \\
G3 & $8.77 \pm 0.66$ & $21.69 \pm 0.79^{\mathrm{a}}$ & $45.47 \pm 1.00$ & $59.44 \pm 0.76^{\mathrm{b}}$ & $27.29 \pm 0.76$ & $40.28 \pm 1.05^{\mathrm{b}}$
\end{tabular}

${ }^{\mathrm{a}} \mathrm{P}<0.05$ vs. the control group. ${ }^{\mathrm{b}} \mathrm{P}<0.05$ vs. TMZ/ACNU alone. ACNU, nimustine; VPA, valproic acid; TMZ, temozolomide.

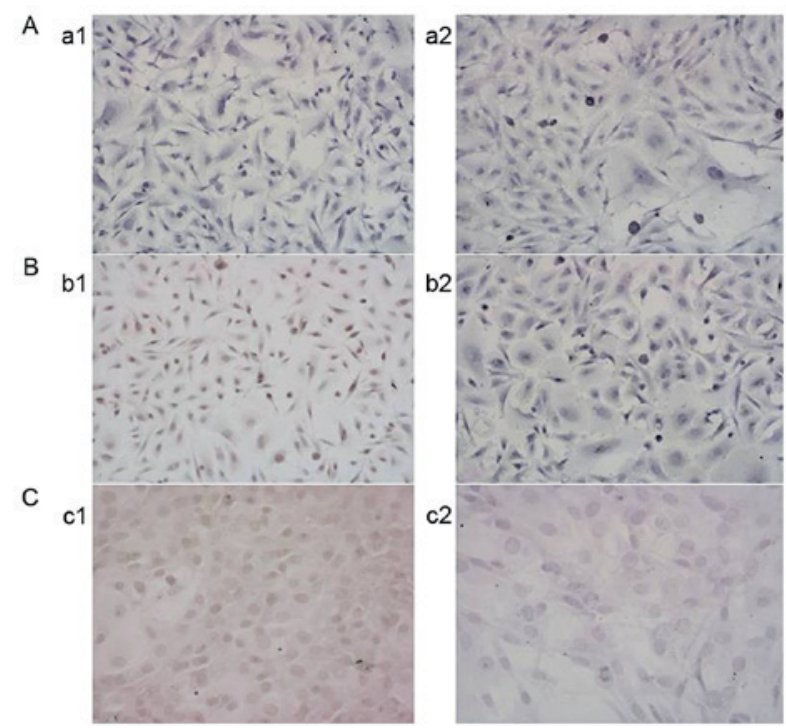

Figure 3. Changes in MGMT expression in glioma stem cells. The expression of MGMT in the (A-a1) G1, (B-b1) G2 and (C-c1) G3 cell populations cultured in VPA-free medium, and MGMT expression in the (A-a2) G1, (B-b2) G2 and (C-c2) G3 cells populations exposed to $1 \mathrm{mmol} / 1$ VPA for 3 days. MGMT, O6-methylguanine-DNA methyltransferase; VPA, valproic acid.

indicated that MGMT expression in the 2 MGMT-positive cell populations (G2 and G3) became negative following VPA treatment, indicating that the expression of MGMT was downregulated by VPA in MGMT-positive glioma stem cells. It was also identified that VPA may downregulate the expression of MGMT in T98 and U138 glioma cell lines by western blot analysis (28). Methylation-specific PCR detection demonstrated that VPA treatment enhanced MGMT promoter methylation in the 3 glioma stem cell populations, suggesting that VPA did not induce the demethylation of MGMT gene promoter region; on the contrary, it may enhance MGMT gene promoter methylation, thereby resulting in the downregulation of MGMT expression, increase in TMZ and ACNU sensitivity in glioma stem cells and enhanced inhibitory effects of TMZ and ACNU on the proliferation of glioma stem cells, finally inducing tumor cell apoptosis. In the MGMT-negative cells, VPA remained able to enhance the inhibitory effects of TMZ and ACNU on cell proliferation, indicating that VPA used other mechanisms to sensitize cells to TMZ and ACNU.

In the clinical setting, VPA is a common an antiepileptic drug, and used in the treatment and prevention of seizures in patients with brain tumors. The anti-glioma effects of VPA suggests that VPA may be the first choice for treatment in patients with glioma to control and prevent seizures, and it may

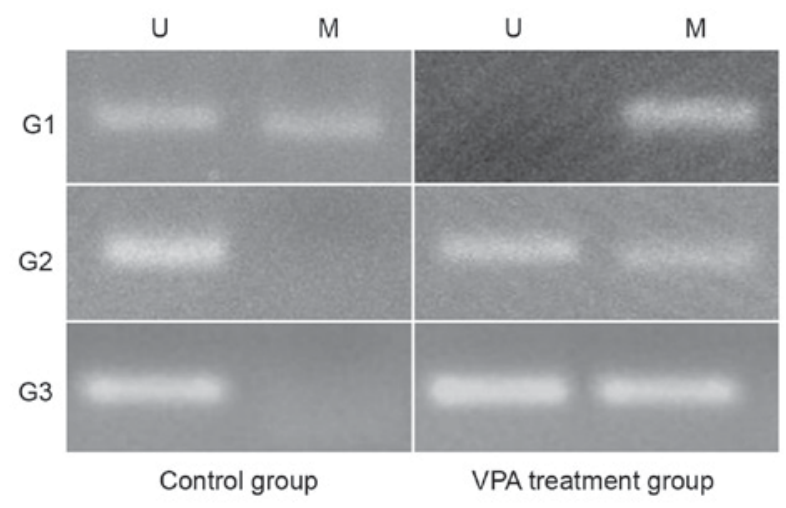

Figure 4. Changes in MGMT promoter methylation. There was partial methylation of G1 cell line in the control group, while complete methylation following VPA treatment, and non-methylation in the G2 and G3 cell populations in the control group, but partial methylation following VPA treatment. U, non-methylated primer amplification; $\mathrm{M}$, the methylation primer amplification; VPA, valproic acid.

enhance the susceptibility of glioma cells to radiation by inhibiting histone deacetylase. In concordance with the results of the present study, it was also demonstrated that VPA downregulated MGMT expression by increasing the level of MGMT gene promoter methylation in glioma stem cells, which enhanced the sensitivity of TMZ and ACNU to glioma cells and the inhibitory effects of TMZ and ACNU on the proliferation, finally resulting in cell apoptosis. This process suggests that patients with glioma may receive chemotherapy plus concomitant and adjuvant VPA. In addition, VPA may also promote the methylation of the MGMT promoter and silence MGMT expression in glioma cells, which may be an important mechanism of VPA enhancing the sensitivity of TMZ and ACNU-targeted glioma stem cells. However, a number of issues in the clinical application of anti-glioma VPA treatment require additional exploration, for example; whether clinical anti-epileptic concentrations produce anti-glioma effects and sensitize glioma cells to radiotherapy and chemotherapy, or whether an established concentration and dosage may be identified to exhibit potential anti-tumor effects as far as possible, without causing serious side effects.

\section{Acknowledgements}

Not applicable.

\section{Funding}

The present study was granted by the Outstanding Talent Project of Henan Province, China (grant no. 084200410011). 


\section{Availability of data and materials}

All data generated or analyzed during this study are included in this published article.

\section{Authors' contributions}

$\mathrm{ZL}$ and $\mathrm{XB}$ conceived the study design and drafted the manuscript. YX and DY participated in the study design and coordination. YY, XG and GZ assisted in study conceptualization, conducted the statistical analysis and contributed to the manuscript draft. ZW and JJ supervised with the data collection and assisted in the implementation of the study. All authors revised and approved the final manuscript.

\section{Ethical approval and consent to participate}

The present study was approved by the Ethics Committee of Zhengzhou No. 7 People's Hospital (Zhengzhou, China). Written informed consent was gained from all participants.

\section{Consent for publication}

All subjects participating in this study have provided their consent for the publication of this data.

\section{Competing interests}

The authors declare that they have no competing interests.

\section{References}

1. Lu B, Zhou Y, Su Z, Yan A and Ding P: Effect of CCL2 siRNA on proliferation and apoptosis in the U251 human glioma cell line. Mol Med Rep 16: 3387-3394, 2017.

2. Dong J, Zhao Y, Huang Q, Fei X, Diao Y, Shen Y, Xiao H, Zhang T, Lan Q and Gu X: Glioma stem/progenitor cells contribute to neovascularization via transdifferentiation. Stem Cell Rev 7: 141-152, 2011.

3. Audia A, Conroy S, Glass R and Bhat KPL: The impact of the tumor microenvironment on the properties of glioma stem-like cells. Front Oncol 7: 143, 2017.

4. Stupp R, Mason WP, van den Bent MJ, Weller M, Fisher B, Taphoorn MJ, Belanger $\mathrm{K}$, Brandes AA, Marosi C, Bogdahn U, et al: Radiotherapy plus concomitant and adjuvant temozolomide for glioblastoma. N Engl J Med 352: 987-996, 2005.

5. Stupp R, Hegi ME, Mason WP, van den Bent MJ, Taphoorn MJ, Janzer RC, Ludwin SK, Allgeier A, Fisher B, Belanger K, et al: Effects of radiotherapy with concomitant and adjuvant temozolomide versusradiotherapy alone on survival in glioblastoma in a randomised phase III study: 5-year analysis of the EORTC-NCIC trial. Lancet Oncol 10: 459-466, 2009.

6. Wakabayashi T, Yoshida J, Mizuno M and Kajita Y: Intratumoral microinfusion of nimustine (ACNU) for recurrent glioma. Brain Tumor Pathol 18: 23-28, 2001.

7. Kaina B, Ziouta A, Ochs K and Coquerelle T: Chromosomal instability, reproductive cell death and apoptosis induced by O6-methylguanine in Mex-, Mex+ and methylation-tolerant mismatch repair compromised cells: Facts and models. Mutat Res 381: 227-241, 1997.

8. D'Atri S, Tentori L, Lacal PM, Graziani G, Pagani E, Benincasa E, Zambruno G, Bonmassar E and Jiricny J: Involvement of the mismatch repair system in temozolomide-induced apoptosis. Mol Pharmacol 54: 334-341, 1998.

9. Brennand $\mathrm{J}$ and Margison GP: Reduction of the toxicity and mutagenicity of alkylating agents in mammalian cell sharboring the Escherichia coli alkyltransferase gene. Proc Natl Acad Sci USA 83: 6292-6296, 1986.
10. Gerson SL: MGMT: Its role in cancer aetiology and cancer therapeutics. Nat Rev Cancer 4: 296-307, 2004.

11. Hegi ME, Diserens AC, Godard S, Dietrich PY, Regli L, Ostermann S, Otten P, Van Melle G, de Tribolet N and Stupp R: Clinical trial substantiates the predictive value of O-6-methylguanine-DNAmethyltransferase promoter methylation in glioblastoma patients treated with temozolomide. Clin Cancer Res 10: 1871-1874, 2004.

12. Hegi ME, Diserens AC, Gorlia T, Hamou MF, de Tribolet N, Weller M, Kros JM, Hainfellner JA, Mason W, Mariani L, et al: MGMT gene silencing and benefit from temozolomide in glioblastoma. N Engl J Med 352: 997-1003, 2005.

13. Göttlicher M, Minucci S, Zhu P, Krämer $\mathrm{OH}$, Schimpf A, Giavara S, Sleeman JP, Lo Coco F, Nervi C, Pelicci PG and Heinzel T: Valproic acid defines a novel class of HDAC inhibitors inducing differentiation of transformed cells. EMBO J 20: 6969-6978, 2001.

14. Kostrouchová M, Kostrouch Z and Kostrouchová M: Valproic acid, a molecular lead to multiple regulatory pathways. Folia Biol (Praha) 53: 37-49, 2007.

15. Michaelis M, Michaelis UR, Fleming I, Suhan T, Cinatl J, Blaheta RA, Hoffmann K, Kotchetkov R, Busse R, Nau H and Cinatl J Jr: Valproic acid inhibits angiogenesis in vitro and in vivo. Mol Pharmacol 65: 520-527, 2004.

16. Riva G, Butta V, Cilibrasi C, Baronchelli S, Redaelli S, Dalprà L, Lavitrano $\mathrm{M}$ and Bentivegna A: Epigenetic targeting of glioma stem cells: Short-term and long-term treatments with valproic acid modulate DNA methylation and differentiation behavior, but not temozolomide sensitivity. Oncol Rep 35: 2811-2824, 2016.

17. Xu H, Song XD, Li Y and Dai J: The new method of cells growing on the glass slide. Zhongguo Ying Yong Sheng Li Xue Za Zhi 25: 283-285, 2009 (In Chinese).

18. Ku JL, Jeon YK and Park JG: Methylation-specific PCR. Methods Mol Biol 791: 23-32, 2011.

19. Chen H, Zhang JH, Li BY, Zhang XQ, Gao HQ, Xu XQ and Wang JFL: The application of hematoxylin stain method in determining the effect of non-monomer herbal extract on the cell proliferation. Chin J Biochem Pharm 31: 183-185, 2010 (In Chinese).

20. Paz MF, Yaya-Tur R, Rojas-Marcos I, Reynes G, Pollan M, Aguirre-Cruz L, García-Lopez JL, Piquer J, Safont MJ, Balaña C, et al: $\mathrm{CpG}$ island hypermethylation of the DNA repair enzyme methyltransferase predicts response to temozolomide in primary gliomas. Clin Cancer Res 10: 4933-4938, 2004.

21. Esteller M, Hamilton SR, Burger PC, Baylin SB and Herman JG: Inactivation of the DNA repair gene O6-methylguanine-DNA methyltransferase by promoter hypermethylation is a common event in primary human neoplasia. Cancer Res 59: 793-797, 1999.

22. Kim JH, Shin JH and Kim IH: Susceptibility and radiosensitization of human glioblastoma cells to trichostatin A, a histone deacetylase inhibitor. Int J Radiat Oncol Biol Phys 59: 1174-1180, 2004.

23. Alvarez AA, Field M, Bushnev S, Longo MS and Sugaya K: The effects of histone deacetylase inhibitors on glioblastoma-derived stem cells. J Mol Neurosci 55: 7-20, 2015.

24. Oi S, Natsume A, Ito M, Kondo Y, Shimato S, Maeda Y, Saito K and Wakabayashi T: Synergistic induction of NY-ESO-1 antigen expression by a novel histone deacetylase inhibitor, valproic acid, with 5-aza-2'-deoxycytidine in glioma cells. J Neurooncol 92: 15-22, 2009.

25. Greenblatt DY, Vaccaro AM, Jaskula-Sztul R, Ning L, Haymart M, Kunnimalaiyaan M and Chen H: Valproic acid activates notch-1 signaling and regulates the neuroendocrine phenotype in carcinoid cancer cells. Oncologist 12: 942-951, 2007.

26. Rodriguez-Menendez V, Gilardini A, Bossi M, Canta A, Oggioni N, Carozzi V, Tremolizzo L and Cavaletti G: Valproate protective effects on cisplatin-induced peripheral neuropathy: An in vitro and in vivo study. Anticancer Res 28: 335-342, 2008.

27. Van Nifterik KA, Van den Berg J, Slotman BJ, Lafleur MV, Sminia P and Stalpers LJ: Valproic acid sensitizes human glioma cells for temozolomide and $\gamma$-radiation. J Neurooncol 107: 61-67, 2012.

28. Ryu CH, Yoon WS, Park KY, Kim SM, Lim JY, Woo JS, Jeong $\mathrm{CH}$, Hou Y and Jeun SS: Valproic acid downregulates the expression of MGMT and sensitizes temozolomide-resistant glioma cells. J Biomed Biotechnol 2012: 987495, 2012.

This work is licensed under a Creative Commons Attribution-NonCommercial-NoDerivatives 4.0 International (CC BY-NC-ND 4.0) License. 